ISSN 0103-5150

Fisioter. Mov., Curitiba, v. 29, n. 1, p. 147-55, Jan./Mar. 2016

Licenciado sob uma Licença Creative Commons

DOI: http://dx.doi.org.10.1590/0103-5150.029.001.A016

\title{
Effects of two programs of metabolic resistance training on strength and hypertrophy
}

\author{
Efeito de dois programas de treinamento resistido com \\ sobrecarga metabólica na força e hipertrofia muscular
}

\author{
Carolina Brandt Meister ${ }^{[\mathrm{a}]}$, Felipe Augusto Tavares Kutianski ${ }^{[\mathrm{b}]}$, Larissa Carine Carstens $\mathbf{s}^{[\mathrm{c}]}$, \\ Sérgio Luiz Ferreira Andrade ${ }^{[b]}$, André Luiz Félix Rodacki ${ }^{[a]}$, Ricardo Martins de Souza ${ }^{[b] *}$ \\ [a] Universidade Federal do Paraná, (UFPR), Curitiba, PR, Brazil \\ [b] CEPAFEE do Centro Universitário Autônomo do Brasil, (UniBrasil) , Curitiba, PR, Brazil \\ [c] Universidade Positivo, (UP), Curitiba, PR, Brazil
}

\begin{abstract}
Introduction: The effects of low intensity resistance training combined with vascular occlusion have been investigated by several studies. Similar results on strength and hypertrophy have been observed when such method was compared to high intensity protocols. However, due to the specific apparatus needed to apply vascular occlusion (ex.: Kaatsu) on some exercises, alternative forms of metabolic training might be used. In the present study, an isometric contraction was performed within each concentric-eccentric transition phase, for every repetition, to elicit metabolic stress. Objective: The aim of the present study was to analyze the effects of two resistance training protocols with metabolic characteristics on strength (1MR), circumference (CIRC) and muscle thickness (measured with ultrasonography [MT]). Subjective perception of discomfort
\end{abstract}

\footnotetext{
* CBM: grad, e-mail: carol_meister@hotmail.com FATK: grad, e-mail: felipe_kutianski@yahoo.com.br LCC: grad, e-mail: lara_carstens@hotmail.com SLFA: Msc, e-mail: slfandrade@yahoo.com ALFR: PhD, e-mail: rodacki@ufpr.br RMS: PhD, e-mail: professor@ricardosouza.pro.br
} 
was also recorded with an analogical-visual pain scale (AVP). Methods: Twelve young, healthy men were trained with two different methods during 10 weeks. The right limb was trained with an isometric contraction within each concentric-eccentric transition phases for every repetition (ISO) whereas the left limb was trained with a pneumatic cuff to apply vascular occlusion (OC) on the knee extensor muscles. Both methods were trained at 20\% 1MR. Results: It was observed increases on medial tight CIRC, proximal MT, medial MT, distal MT and 1MR, with no difference between both methods. The perception of discomfort was greater for ISO at the end of the third set and lower than reported by OC, at the beginning and end of the training program. Conclusions: Both protocols produced similar gains on strength and hypertrophy. The advantages of training with low loads are important to elderly or rehabilitation training programs. Other studies that compare this method with conventional resistance training are warranted.

Keywords: Isometric. Kaatsu. Resistance. Raining. Hypertrophy.

\section{Resumo}

Introdução: Estudos têm avaliado os efeitos do treinamento resistido de baixa intensidade combinado com oclusão sanguínea. Este método vem sendo comparado a protocolos de alta intensidade, e resultados semelhantes de aumento de força e hipertrofia têm sido observados. Entretanto, na dificuldade em instrumentalizar a oclusão vascular com garrote (ex.: Kaatsu) em alguns exercícios resistidos, outras formas de execução são realizadas, como as que associam a utilização de intervalos em contração isométrica. Objetivo: $O$ objetivo do estudo foi analisar os efeitos de dois protocolos de treinamento resistido de características metabólicas nos ganhos de força (1RM), circunferência (CIRC), espessura muscular (ultrassonografia [ESP]), e percepção subjetiva do desconforto (EVA). Métodos: Doze homens jovens e saudáveis foram treinados com dois métodos por 10semanas. No membro inferior direito foi realizado o treinamento resistido com intervalo isométrico (ISO) e no membro inferior esquerdo o treinamento com oclusão vascular (OCL) no exercício de extensão do joelho. 20\% de 1RM em ambos os métodos. Resultados: Encontraram-se aumentos em ambos os métodos na CIRC, ESP proximal, ESP medial, ESP distal e 1RM. A EVA ao final da terceira série de exercícios aumentou no ISO, sendo menor que a relatada no OCL. Não foram encontradas outras diferenças entre os métodos utilizados. Conclusões: Deste modo, ambos os sistemas utilizados produziram efeitos similares nos ganhos de força e hipertrofia. As vantagens de ambos os métodos consistem no uso de cargas reduzidas, podendo ser importante para o treinamento em idoso ou programas de reabilitação. Estudos que comparem os métodos aqui utilizados com o treinamento resistido convencional devem ser realizados.

Palavras-chave: Isometria. Kaatsu. Musculação. Hipertrofia.

\section{Introduction}

Over the past few years, several studies have sought to identify ways to achieve the development of strength and muscle mass. To this end, distinct methods have been used for training the human body, since the skeletal muscle has the ability to respond to stimulation adapting to mechanical stress. However, this response can vary between different exercise modes (1).

Certain methods of trainingmight bemore appropriate than others for precise application and systematic overload, and may have different forms of application. Thus, resistance training (RT) is one of the best options to enhance athletic performance, increase muscle strength, power, balance and
coordination.This may explain why there is a growing number of supporters of this practice worldwide. The RT presents various methods for the development of the qualities mentioned above, using both mechanical or metabolic stress. Discrepancy among the opinions regarding the best training methods have been sustained for a long period of time, until recent studies have been published comparing both methods.

However, some problems related to resistance training may also limit its effects. For instance, the need of long recovery periods is often not respected by practitioners, making it potentially harmful and uncomfortable. Some methods consist in performing intermittent isometric contractions coupled with dynamic training (2) and training with blood vascular 
occlusion, which may be applied into training programs in order to securely maximize gains in strength and muscle mass (3). It is believed that both methods cause large metabolites accumulation in muscle during exercise, which along with other factors, can lead to significant gains in strength and muscle mass with little mechanical stresson the soft tissues and bones. Furthermore,lower discomfort may be reported from such method compared to high load training.It has been demonstrated that concentric actions interspersed with isometric contractions in the concentric-eccentric transition produce a greater accumulation of metabolites, compared with protocols without isometrics (2). One possible explanation for this phenomenon is that the compression in the shortened muscle generates tension over the capillaries, creating a blood flow restrictionand thereby decreasing the rate of removal of metabolites. The specific mechanisms behind metabolic stress to elicit hypertrophy are unclear. However, several studies have shown expressive increases in strength and hypertrophy from metabolic training $(2,4)$ and blood flow occlusion $(3,5,6,7,8,9,10,11,12,13,14)$, compared to traditional high intensity training.

Both methods (occlusion and isometric metabolic training) have unique features in their application, which can lead to different responses. No studiesare knownregarding training with blood occlusion compared to isometric metabolic training. Therefore, the present study aimed to compare the effects of twolow-load protocols onmuscle strength and hypertrophy and the subjective perception of discomfort.

\section{Methods}

Twelve healthy men $(23.92 \pm 25 y r s, 1.75 \pm$ $0.07 \mathrm{~m}, 69.28 \pm 9.79 \mathrm{~kg}, 12.36 \pm 3.39 \%$ body fat) undergraduate in physical education volunteered to participate in this study. Prevous injury and/or musculoskeletal disordersand regular use of medications that could interfere in exercise execution were adopted as exclusion criteria. The participantsdid not participate in any other program of regular physical activity and have the availability to participate the sessions in the days and predetermined times. All participants signed a consent form, based on the 196/96 resolution of the CNS approved by the UniBrasil University Centre Ethics Committee under number 06/2011.
All assessments were conducted by the same experienced instructors at the beginning (PRE) and end (POST) of the exercise program. Body mass and height were measured with an anthropometric scale (Welmy, Santa Barbara D'Oeste, Brazil), while body fat was determined by bioimpedance (Body Fat Scale, Geratherm) according toDonini et al. (15).

Thigh length (LEFT and RIGHT) was determined as the distance between the lateral aspect of the greater trochanter of the femur and the upper edge of the patella. This segment was divided into three equal parts, and the circumference measures (CIRC) and muscle thickness (MT on the anterior surface) by ultrasound (Logic Book XP, GE, USA) were measuredat the proximal (PROX), medial (MED) and distal (DIST) third of thigh.

All subjects were placed sitting with the knees flexed at $90^{\circ}$ and both feet in full contact with the ground. All ultrasound images were obtained in a sagittal plane at the three sites mentioned above. The scanner was positioned perpendicular to the skin surface and set to $6 \mathrm{~Hz}$ and $9 \mathrm{~cm}$ depth in order to provideclear visualization of the femur cortical surface. MT was determined by the linear distance between the fat-muscle interface to the muscle-bone interface. This procedure is similar to that used in other studies for the same purpose and has high reliability (16).

Maximum strength tests were performed at the beginning and at the end of the training program. All measurements were conducted in the same week, with a minimum interval of 48 hours. The highest value obtained in the test between the two sessions was considered for analysis. The 1-MR(maximum repetition) prediction protocol was adopted from a submaximal strength test, using the equation Brzycki, validated for the Brazilian population by Nascimento et al. (17). In this test, a submaximal exercise is performed and the value of 1-MR is calculated as the following:

$$
1-\mathrm{MR}=100 * \operatorname{load} /(102.78 \text { to } 2.78 * \text { repetitions })
$$

Where "load" is the mass (kg) used in equipment where the test was performed and "repetition" is the number of repetitions performed with the determined load. We opted for the use of this protocol due to load shedding provided by the equipment used in the test, the greater security offered by smaller overloads and high correlation of the test with the pattern of 1-MR $(r=0.89)$ found a validation study (17). 
Individuals began the exercises one week after the assessments. Training sessions lasted for 10 weeks, with a frequency of twice a week, with a minimum interval of 48 hours and a maximum of 96 hours between sessions, all training conducted under the supervision of the same instructor. A single exercise was conducted in the leg extension equipament. None of the participants missed more than three exercise sessions, or two consecutive sessions, which automatically excluded the subject of the study.

The RIGHT was subjected to a resistance exercise consisting of concentric and eccentric contractions, interspersed by an isometric contraction (ISO), based on the model proposed by Gentil et al. (2). Exercise in leg extension began with the knee flexed at $90^{\circ}$. The exercise began with concentric phase of the exercise and then a five-second interval with the extended limb (ISO). It is performed three sets of eight to 12 consecutive repetitions with an interval of 30 seconds between sets. The load applied in the first exercise session was $20 \%$ of 1 -MR predicted initially. After the first session, the load was continuously adjusted so that the maximum range of repetitions in each series was not exceeded. Adjustments in the load were performed with $5 \mathrm{~kg}$ increments whenever was needed.

In LEFT the exercise protocol used was based on the training model with vascular occlusion (OC) described by Sato and Abe (3). Subjects wereseatedon the leg extension machine with a sphygmomanometer (MERCUR, SP) around the proximal third of thethigh. It was then inflated to $160 \mathrm{mmHg}$. Three sets of eight to 12 reps were performedwith 30 seconds rest between sets. The cuff pressure was maintained during rest intervals and throughout the sets, with adjustments whenever necessary. After completion of each setthe visual analog scale (VAS) was applied to record perception of discomfort, as adapted by Hernandez (18).

The VAS (Figure 1) is a subjective method to assess muscle pain.In the present study, it was used in order to identify the discomfort caused by the exercise protocol andtoverify an adaptation to discomfort was happenedwith possible reduction in pain intensity. The VAS was used at the beginning (first session) and at the end of the 10 weeks (last session) in three moments during the execution of the exercises in both the RIGTH and LEFTlimbs: shortly after the end of the first set (VAS-1), shortly after the end of the third set (VAS-3) and five minutes after (VAS-5) the end of the training session. Figure 2 shows a schematic organization of the training program.

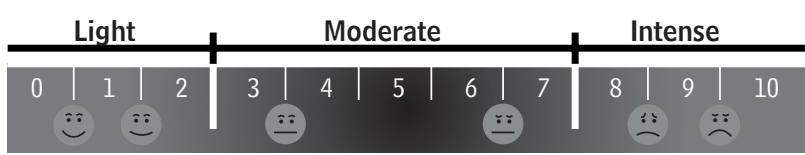

Figura 1 - Analogical pain scale adapted by Hernandez (18)

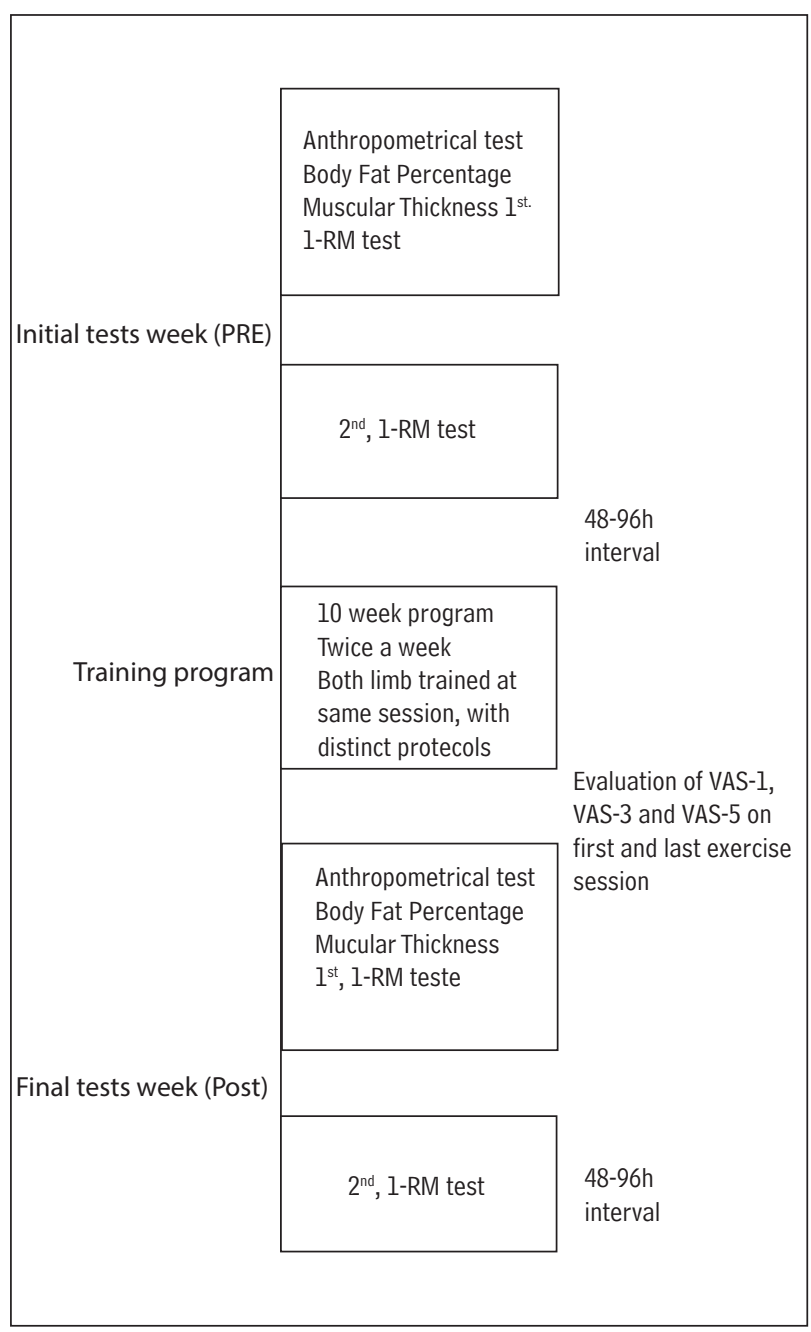

Figura 2 - Organization of experimental procedures

After the data normality was confirmed withthe Kolgomorov-Smirnov test, analysis of variance (ANOVA) for repeated measures was applied to comparethe differences between the beginning (PRE) and the end (POST) of each training program and between methods. Significance level was set to $\mathrm{p} \leq 0.05$ for all variables. A post-hoc test (Tukey) was used to identify where the differences occurred. All analysis was carried out using Statistica software v 7.0. 


\section{Results}

All 12 subjects completed the exercise program. No initial (PRE) significant differences were found $(p \geq 0.05$ ) between any variables. The anthropometric characteristics (PRE $69.28 \pm 9.79 \mathrm{~kg}$ and 12.36 $\pm 3.39 \%$ fat) did not change significantly ( $p>0.05$ ) after exercise program (POST $69.04 \pm 9.26 \mathrm{~kg}$ and $12.81 \pm 5.01 \%$ fat). The measures of CIRC-PROX and CIRC-DIST showed no significant differences ( $p>0.05$ ) between PRE and POST in both methods. Increases in CIRC-MED were found at the end of both programs (ISO and OC).

All ultrasound measurements showed a significant increase $(\mathrm{p} \leq 0.05)$ between PRE and POST from both ISO and OC training. No differences were found $(\mathrm{p}>$ 0.05 ) between methods. Muscle strength increased ( $p \leq 0.05$ ) for bothtraining methods. The PRE values of VAS-1 showed no difference between the ISO and
OC training at the end of the first series of exercises (ISO $3.25 \pm 209$, OC $3.58 \pm 1.68$ ). However, at the end of the third series of exercises the OC system showed a value significantly ( $\mathrm{p} \leq 0.05$ ) higher on VAS-3 (OC $9.25 \pm 1.22$, ISO $7.08 \pm 2.15$ ) and VAS- 5 (OC 1.83 \pm 1.47 , ISO $0.17 \pm 0.58$ ). At the end of the exercise program the VAS- 1 values did not change $(p>0.05)$ in both the ISO and OC training. VAS-3 values in ISO training increased $(\mathrm{p} \leq 0.05)$ increase between the PRE and POST assessments. In OC the VAS-3 measure showed no change between assessments ( $p>0.05)$. The VAS- 5 has not been changed $(p>0.05)$ between assessments in ISO training. In OC training, VAS-5 showed a significant $(\mathrm{p} \leq 0.05)$ reduction due to the exercise program. At the end of each training sessions, the comparison between ISO vs. OC showedhigher VAS-3 values ( $\mathrm{p} \leq 0.05)$ in OC training compared to ISO training ( $8.75 \pm 1.36$ ). The comparisons between variables are presented in Table 1.

Table 1 - Anthropometrics, kinetics and pain variables at beginning (PRE) and the end (POST) of isometric (ISO) and vascular occlusion (OC) training programs

\begin{tabular}{|c|c|c|c|c|}
\hline & \multicolumn{2}{|c|}{ ISO } & \multicolumn{2}{|c|}{$\mathrm{OC}$} \\
\hline & Pre & Post & Pre & Post \\
\hline CIRC-PROX (cm) & $55.71 \pm 4.84$ & $55.88 \pm 5.22$ & $55.45 \pm 5.18$ & $54.89 \pm 4.74$ \\
\hline CIRC-MED (cm) & $51.19 \pm 4.84$ & $52.67 \pm 4.14^{*}$ & $51.43 \pm 4.39$ & $52.46 \pm 4.29 *$ \\
\hline CIRC-DIST (cm) & $42.93 \pm 4.41$ & $44.35 \pm 3.33$ & $43.13 \pm 4.20$ & $43.67 \pm 3.52$ \\
\hline MT-PROX (cm) & $18.83 \pm 4.00$ & $21.83 \pm 3.97^{\star}$ & $17.00 \pm 4.18$ & $21.67 \pm 3.42^{\star}$ \\
\hline MT-MED (cm) & $18.33 \pm 3.60$ & $20.58 \pm 3.34^{*}$ & $18.17 \pm 3.33$ & $20.67 \pm 3.26^{*}$ \\
\hline MT-DIST (cm) & $12.67 \pm 3.82$ & $15.83 \pm 3.21^{*}$ & $12.00 \pm 2.52$ & $15.42 \pm 2.97^{\star}$ \\
\hline 1-RM (kg) & $97.66 \pm 11.35$ & $131.73 \pm 14.07^{*}$ & $95.52 \pm 13.85$ & $137.28 \pm 15.00$ * \\
\hline VAS-1 & $3.25 \pm 2.09$ & $2.25 \pm 1.76$ & $3.58 \pm 1.68$ & $1.67 \pm 2.42$ \\
\hline VAS-3 & $7.08 \pm 2.15$ & $8.75 \pm 1.36^{*}$ & $9.25 \pm 1.22$ ** & $9.08 \pm 1.31^{* *}$ \\
\hline VAS-5 & $0.17 \pm 0.58$ & $0.17 \pm 0.39$ & $1.83 \pm 1.47$ & $1.00 \pm 0.85^{\star}$ \\
\hline
\end{tabular}

Note: $\left({ }^{*}\right)$ significant statistical differences between the beginning (PRE) and the end (POST) of programs; $\left({ }^{* \star}\right)$ significant statistical differences between ISO e OC methods.

\section{Discussion}

It is well known that RT with vascular occlusion produces significant gains in strength and muscle hypertrophy $(5,11,19,20)$. One of the advantages attributed to this method is the possibility to stimulate similar chronic adaptations obtained with traditional methods, without using high loads. However, Kawada (21) questions the safety of vascular occlusion for people with vascular disorders (eg.: thrombosis and hypertension) and claims that this type of training would not be the only methodthatcan produce a stimulus at relatively low loads. Gentil et al. (2) showed that it is possible to manipulate the variables of the traditional training (repetitions ranges, contraction types, etc.) to yield a metabolic overload. There are no known studies that have compared the effects of two training systems with metabolic overload, with (OC) 
and without (ISO) vascular occlusion. The results of this study suggest that the traditional training without occlusion can produce similar effects to training with occlusion.

Strength gains obtained in both systems (ISO and OC) corroborate the findings of other studies $(22,23)$, which showed that strength training does not necessarily depend on the large tensions produced by the muscles, contrary to previous studies (24). The load applied in our study (20\% 1-MR) did not represent a significant mechanical stress, suggesting that the gains in strength were not stimulated by structural damage to contractile proteins, but changes in local metabolic conditions. In ISO system, isometric contractions were performed with the intention of inducing ischemia and thus increase the metabolic stress. This effect confirms the study of Gentil et al. (2), which showed that a protocol with concentric and eccentric actions, interspersed with isometric contractions produced higher blood lactate levels compared to a 10-MR continuous protocol without isometrics. In that study, the authors noticed that there is not a direct causal relation between the muscle adaptations and lactate, but lactate can be used as a physiological marker of metabolic stress.

In our study, the isometric contractions appeared to play an important role in the effects of occlusion without training. Each repetition was interspersed with an isometric contraction held for five seconds at full extension of the knee. Schott et al. (25) had already been shown that continuous isometric contractions for 30 seconds were more efficient to produce hypertrophy compared to 10 intermittent contractions three seconds with two seconds between each repetition. The authors observed a greater decrease in blood $\mathrm{pH}$ levels with the prolonged contractions and attributed the grater gains to metabolic changes. In our study, the limb trained with occlusion did not perform isometric contractions, which demonstrates the importance of this type of contraction in traditional training, when the goal is to produce metabolic stimuli.

Although there had been no changes in the thigh circumference, the increases $(p \leq 0.05)$ in the MTPROX, MT-MED and MT-DISTmeasures showed that both OC and ISO were efficient to hypertrophy of the knee extensor muscles. The absence of differences $(p>0.05)$ between groups suggests that isometric contractions without occlusion were sufficient to produce metabolites accumulation. These findings were discrepant with Takarada et al. (23), which demonstrated that the group who trained with occlusion showed greater hypertrophy,despite the lower load. In that study, they compared the effects of $50 \%$ of $1 \mathrm{RM}$ with vascular occlusion and $80 \%$ of $1 \mathrm{RM}$ without occlusion. The authors attributed the results to a greater recruitment of muscle fibers in the exercise with occlusion, resulting in increased lactate levels. The mechanisms by which the decrease in $\mathrm{pH}$ affects the hypertrophy are still not completely known. It is known that the secretion of hGH (human Growth Hormone) increases in intramuscular acidosis conditions and thus positively influence hypertrophy (9) through inhibition of myostatin expression of a gene regulator that limits the muscle growth. However, changes in blood lactate are not necessarily indicative of direct changes in the levels of this hormone (26). Several studies have attempted to elucidate the physiological mechanisms that generate chronic adaptations to training with occlusion. Among the various factors, it is believed that the restriction of venous blood flow may enhance coordination intramuscular, through the activation of a larger number of type II fibers. It is also known that the decrease in supply of oxygen generate an activation of reactive oxygen species (ROS), which cause cellular damage and lipid peroxidation, the deactivation of enzymes and DNA damage $(1,9,21,26)$. In addition to neural and intracellular factors, the literature has shown correlations between hypoxia, accumulation of metabolites and acute secretion of various hormones such as hGH, IGF-1, testosterone, among others $(1,27)$.

The growing research regarding metabolic stress as a training stimulus has given rise to several hypotheses that attempt to explain this phenomenon. One is the recruitment of fast fibers at low intensities. The Henneman's principle (also called size principle) proposes that larger drive motor withhigher excitation thresholds are recruited asthe intensity of the exercise increases. However, studies using vascular occlusion and electromyography showed that there was an increase in the recruitment of fast fibers, even with low intensity loads $(28,29,30)$. One speculation about this effect is the fatigue caused by the hydrogen ion accumulation from the anaerobic glycolysis. It is believed that with the fatigue, inhibition of contractility of slow twitch fibers promotes the recruitment of fast-twitch fibers, which have greater hypertrophic potential, to sustain the force required by the muscle (31). Another proposed mechanism is the acute 
increase in hormonerelease, which increases protein synthesis signaling and, consequently, muscle growth. For example, Abe et al. (31) found an increased concentration of IGF-1 with occlusion training, suggesting an influence of this metabolic stress hormone. The hGH was also shown to be strongly related to the accumulation of metabolites, as showed by Takarada et al. (32) who reported increases of 290 times the basal level of hGH after a vascular occlusion protocol. It is believed that this response is stimulated by muscular acidosis and accumulation of metabolites, mediated metaboreceptors and afferent fibers of groups III and IV (33). Testosterone is another hormone crucial for hypertrophy, given their increasing role in protein synthesis and decreased proteolysis. However, several studies have found significant elevations in testosterone elevations due to training with vascular occlusion, even despite the elevated metabolic stress $(27,34)$.

In a review study, West and Phillips (35) contested the importance of post-exercise acute increases in the concentration of anabolic hormones for hypertrophy. According to that review, the acute responses of hGH and testosterone are not predictors of hypertrophic response and do not reflect proportionally its mechanisms. The authors also suggested that local changes specific to the stimulated muscle are more important than the systemic changes induced by exercise. Another recent hypothesis that may explain the hypertrophy through metabolic stress generated by vascular occlusion is the theory of cell swelling. It is believed that immediately after the occlusion ceased, reactive hyperemia in the blood vessels of the exercising muscle (36) and osmotic changescause an abrupt increase in intracellular hydration. Thus, the pressure against the cell membrane can be perceived as a threat to the integrity of the cell, which according to this hypothesis, could trigger the signaling of growth factors thought likely to enhance its ultra-structure (37). This study cannot confirm or refute such hypotheses to explain the hypertrophy, as changes at the cellular or plasma levels have not been investigated. However, the results confirmed an effect of chronic metabolic stimulus for hypertrophy. The main finding of this study was the possibility of adapting a traditional resistance training protocol to produce similar magnitude of hypertrophy obtained froma training protocol with vascular occlusion. Our data suggest a methodological approach between two forms of training that can cause the same metabolic stress for the purpose of muscular hypertrophy.

The visual analogue scale (VAS) was used as a subjective parameter for assessing the sense of muscle pain during the execution of the two training systems. The discomfort reported at the end of the third series showed that both protocols may have produced high levels of intramuscular acidosis. The highest values recorded in $\mathrm{OC}$ can be explained by the restrained removal of local metabolites caused by the continued restriction of the venous blood flow. On the other hand, in ISO the 30 second rest might be partially allowed this removal. In our study blood lactate was not quantified because both ISO and OC methods were applied to both limbs of the same subjects, which hindsthe individual analysis of each method. Regarding the pain scale, there is an increase of the reported values between PRE and POST collections for VAS-3 value in the ISO system. A possible explanation for this finding is theincreased neuromuscular coordination during the isometric contractions, which resulted in increased recruitment of fibers and, consequently, higher acidosis to be supported by the subject. This observation may suggest that, with the improvement of neuromuscular ability in training, the subjects are capable of producing greater discomfort during exercise. The short duration (10 weeks) was one limitation of this study. It is known that with training, the rate of strength gains and hypertrophy tends to decrease.Thus, we cannot claim that the gainsobserved would similarly continue for longer periods. Further studies with longer training periods with intermediate measures are warranted. Another limitation has been the absence of measures of physiological markers to compare the acute effects of both protocols.

\section{Conclusion}

Training without vascular occlusion showedsimilar effects on strength and hypertrophy,compared to training with occlusion. The advantages of both methods are the use of relatively low loads, which is of particular importance to the elderly, often present in articular cartilage degenerative conditions (e.g. arthrosis). Thus, metabolic training without vascular occlusion can be as efficient as training with occlusion, whenthe goal is to preserve joint structures. Other applications are post-surgery rehabilitation 
or throughout training periodization of athletes after the competition phase. The isometric contractions may be a key element in the prescription of resistance exercise with metabolic stress. Despite the evidencesaboutthe effectivenessof training with vascular occlusion, such method requires specific apparatus (cuff) for pressure control and may not be suitable for people with vascular fragility or chronic high blood pressure.

\section{References}

1. Karabulut M, Abe T, Sato Y, Bemben M. Overview of neuromuscular adaptations of skeletal muscle to KAATSU Training. Intern J KAATSU Train Res. 2007; 3:1-9.

2. Gentil P, Oliveira E, Bottaro M. Time under Tension and Blood Lactate Response during Four Different Resistance Training Methods. J PhysiolAnthropol. 2006;25:339-44.

3. Sato Y, Yoshitomi A, Abe T. Acute growth hormone response to low-intensity KAATSU resistance exercise: Comparison between arm and leg. Intern J KAATSU Train Res. 2005;1:45-50.

4. Keogh J, Wilson G, Weathrby R. A cross-sectional comparison of different resistance training techniques in the bench press. J Stren Cond Res. 1999;13(3):247-58.

5. Yasuda T, Abe T, Sato Y, Midorikawa T, Inouce C, Ryushi T, Ishii N. Muscle fiber cross-sectional area is increased after two weeks of twice daily KAATSU-resistance training. Intern J KAATSU Train Res. 2005;1:65-70.

6. Abe T, Ozaki H, Sugaya M, Fujita S, Sakamaki M, Sato Y, Bemben MG. Effects of 42 weeks walk training with blood flow reduction on muscle size and strength in the elderly. Intern Conf Sports Ex Sci. 2009;336-41.

7. Iida $\mathrm{H}$, Kurano $\mathrm{M}$, Takano $\mathrm{H}$, Oonuma $\mathrm{H}$, Imuta $\mathrm{H}$, Kubota N, Morita T, Meguro K, Sato Y, Abe T, Yamazaki T, Nakajima T. Can KAATSU be used for an orthostatic stress in astronauts?: A case study. Intern J KAATSU Train Res. 2006;2:45-52.

8. Karabulut M, Abe T, Sato Y, Bemben M. The effects of low-intensity resistance training with vascular restriction on leg muscle strength in older men. Euro J App Physiol. 2010;108:147-55.
9. Laurentino G. Treinamento de força com oclusão vascular: Adaptações neuromusculares e moleculares. [Thesis] Escola de Educação Física e Esporte da Universidade de São Paulo, 2010.

10. Takano H, Morita T, Iida D, Kato M, Uno K, Hirose K, Matsumoto A, Takenaka A, Hirata Y, Furuichi T, Eto F, Nagai R. Effects of low-intensity "KAATSU" resistance exercise on hemodynamic and growth hormone responses. Intern J KAATSU Train Res. 2005;1:13-8.

11. Loenneke JP, Faghs CA, Rossow LM, Abe T, Bemben MG. The anabolic benefits of venous blood flow restriction training may be induced by muscle cell swelling. Med Hypotheses. 2012;78:151-4.

12. Loenneke JP, Pujol TJ. KAATSU: Rationale for application in Astronauts. HIPPOKRATIA. 2010;14:223-4

13. Ozaki H, Sakamaki M, Yasuda T, Fujita S, Ogasawara R, Sugava M, Nakajima T, Abe T. Increases in Thigh Muscle Volume and Strength by Walk Training with Leg Blood Flow Reduction in Older Participants. J Gerontol A BiolSci Med Sci. 2011;66A(3):257-263.

14. Clarck BC, Manini TM, Hoffman RL, Williams PS, Guiler MK, Knutson MJ, McGlynn ML, Kushnick MR. Relative safety of 4 weeks of blood flow restricted resistance exercise in young, healthy adults. Scand J Med Sci Sports. 2011;21:653-62.

15. Donini LM, Poggiogalle E, del Balzo V, Lubrano C, Faliva M, Opizzi A, Perna S, Pinto A, Rondanelli M. How to estimate fat mass in overweight and obese subjects. Intern J Endocrinol. 2013;9.

16. Gentil P, Soares SRS, Pereira MC, Cunha RR, Martorelli SS, Martorelli AS, Bottaro M. Effect of adding singlejoint exercises to a multi-joint exercise resistance-training program on strength and hypertrophy in untrained subjects. Appl Physiol Nutr Metab. 2013;38:341-4.

17. Nascimento MA, Cyrino ES, Nakamura FY, Romanzini M, Pianca HJC, Queirógas MR. Validação da equação de Brzycki para a estimativa de 1-MR no exercício supino em banco horizontal. Rev Bras Med Esp. 2007;13:1.

18. Hernandez S. Influência da crioterapia de imersão em indicadores de dano muscular pós exercício em atletas de triathlon. [Dissertation]; Universidade Federal do Paraná, 2010. 
19. Fry C, Glynn E, Drummond M, Timmerman K, Fujita S, Abe T, Dhanani S, Volpi E, Rasmussen BB. Blood flow restriction exercise stimulates mTORC1 signaling and muscle protein synthesis in older men. J App Physiol. 2010;108:1199-209.

20. Loenneke J, Wilson J, Marín P, Zourdos M, Bemben M. Low intensity blood flow restriction training: a meta-analysis. Euro J App Physiol. 2011.

21. Kawada S. What phenomena do occur in blood flowrestricted muscle? Intern J KAATSU Train Research. 2005;1:37- 44.

22. Shinohara M, Kouzaki M, Yoshihisa T, Fukunaga T. Efficacy of tourniquet ischemia for strength training with low resistance. Euro J App Physiol. 1998;77:189-91.

23. Takarada Y, Takazawa H, Sato Y, Takebayashi S, Tanaka, Y, Ishii N. Effects of resistance exercise combined with moderate vascular occlusion on muscular function in humans. J App Physiol. 2000;88:2097-106.

24. McDonagh MJN, Davies CTM. Adaptive response of mammalian skeletal muscle to exercise with high loads. Euro J App Physiol. 1984;52:139-55.

25. Schott J, McCully K, RUTHERFORD OM. The role of metabolites in strength training II. Short versus long isometric contractions. Euro J App Physiol 1995;71(4):337-41.

26. Loenneke J. The use of occlusion training to produce muscle hypertrophy. Strength Condit J. 2009;31: 3.

27. Reeves G, Kramer R, Hollander D, Clavier J, Thomas C, François M, Castracane VD. Comparison of hormone responses following light resistance exercise with partial vascular occlusion and moderately difficult resistance exercise without occlusion. J App Physiol. 2006;101:1616-22.

28. Loenneke JP, Faha CA, Wilson JM, Bemben MG. Blood flow restriction: the metabolite/volume threshold theory. Med Hypotheses. 2011;77(5):748-52.

29. Loenneke JP, Abe T, Wilson JM, Thiebaud RS, Fahs CA, Rossow LM, Bemben MG. Blood flow restriction: an evidence based progressive model (Review). Acta Physiol Hungarica.2012;99(3):235-50.

30. Meyer RA. Does blood flow restriction enhance hypertrophic signaling in skeletal muscle? J Appl Physiol. 2006;100(5): 1443-4.
31. Abe T, Yasuda T, Midorikawa T, et al. Skeletal muscle size and circulating IGF-1 are increased after two weeks of twice daily KAATSU resistance training. Int J Kaatsu Train Res. 2005;1: 6-12.

32. Takarada Y, Nakamura Y, Aruga S, Onda T, Miyazaki $\mathrm{S}$, Ishii N. Rapid increase in plasma growth hormone after low-intensity resistance exercise with vascular occlusion. J Appl Physiol. 2000;88(1):61-5.

33. Loenneke JP, Wilson GJ, Wilson JM. A mechanistic approach to blood flow occlusion. Int J Sports Med. 2010;31(1):1-4.

34. Viru M, Jansson E, Viru A, et al. Effect of restricted blood flow on exercise-induced hormone changes in healthy men. Eur J Appl Physiol Occup Physiol. 1998;77(6):517-22.

35. West, D, Phillips S. Anabolic processes in human skeletal muscle: restoring the identities of growth hormone and testosterone. The Physi and Sportsmed 2010;38(3):97-104.

36. Wesche J. The time course and magnitude of blood flow changes in the human quadriceps muscles following isometric contraction. J Physiol. 1986;377:445-62.

37. Lang F. Mechanisms and significance of cell volume regulation. J Am Coll Nutr. 2007;26(5):613S-23S.

Recebido:24/05/2013

Received: 05/24/2013

Aprovado: $12 / 08 / 2015$

Approved: 08/12/2015 
